\title{
Bearing Characteristics of Diaphragm Wall Foundation under Vertical and Combined Load
}

\author{
Hao Huang ${ }^{1}$ (iD), Cheng Wang ${ }^{1}$ (D), Weiming Gong ${ }^{*},{ }^{2}$, (iD), Huanan Xu ${ }^{4}$ (D) \\ ${ }^{1}$ Anhui Transport Consulting \& Design Institute Co., LTD, Hefei 230088, Anhui, China \\ ${ }^{2}$ Key Laboratory of Concrete and Prestressed Concrete Structures of Ministry of Education, Southeast University, Nanjing \\ 210096, Jiangsu, China \\ ${ }^{3}$ School of Civil Engineering, Southeast University, Nanjing 210096, Jiangsu, China \\ ${ }^{4}$ Changzhou Architectural Research Institute Group CO., LTD, Changzhou 213000, Jiangsu, China
}

\section{Keywords}

Finite element models,

Mobilization mechanism,

Combined load,

Eight-component Winkler spring model,

Calculation methods of rigid pile displacement,

Overall overturning failure.

\begin{abstract}
To investigate the bearing characteristics of diaphragm wall foundation under combined load, the results from elasto-plastic analyses of 3D finite element models (FEM) were presented in this study. The vertical load of the diaphragm wall foundation is borne by inner and outer side resistance, resistance of soil core and the end of wall, respectively. Moreover, the sum of end resistance and soil core resistance accounts for about $75 \%$ of the vertical load. The mobilization mechanism and distribution of side resistance of the foundation were also analyzed. It is clarified that the mobilization characteristics of inner and outer side resistance of the wall are completely opposite. Due to the combined load, the horizontal load has an amplification effect on the settlement of the foundation. Additionally, the calculation methods of the Eight-component Winkler spring model and rigid pile displacement were used for determining the vertical load-bearing capacity and the overturning stability. A comparison between results from the FEM and the theoretical calculation methods showed that the results of the numerical simulation properly coincided with that of the displacement solution of theoretical model. The conclusions obtained by the above methods all indicate that the foundation has the characteristics of overall overturning failure under the combined load.
\end{abstract}

\section{Introduction}

In recent years, diaphragm wall has been used extensively in the building facilities, such as high-rise buildings, bridges and subway. Diaphragm wall foundation has great advantages in reducing the construction cost and shortening the construction period. In bridge engineering, such as arch bridge, the foundations are usually subjected to a vertical loading with a horizontal loading and a moment. Such a loading mode is defined as a combined loading mode.

Taiebat and Carter (2000) [1] employed the FEM to investigate the behavior of suction bucket foundation under a combination of axial, lateral and torsional forces, where it was shown that the torsional force obviously reduced the axial and lateral capacities. Wang and Jin (2008) [2] investigated the effects of overturning moment on the bearing capacity of the suction bucket by the FEM, the results have shown that the overturning moment induced by the eccentric horizontal force reduced the axial capacity. Lian et al. (2011) [3] presented a calculation method for the horizontal ultimate bearing capacity and the overturning resistance. Le and Sung (2012) [4] proposed equations for the vertical and horizontal load-bearing capacities based on finite element analysis results. Liu et al. (2014) [5] proposed simplified calculation methods for calculating the vertical load-bearing capacity and the overturning stability of the wideshallow bucket foundation. The comparison between the results of FEM and the simplified calculation methods shows that the proposed equations properly predicted the capacities of the wide-shallow bucket foundations.

Fan et al. (2018) [6] implemented the searching algorithm for the optimal load reference point to obtain a unified equation to describe the shapes of failure envelopes for skirted foundations, which can be simply applied to express the 3D failure envelopes of skirted foundations on both isotropic and anisotropic clay. Vulpe et al. (2013) [7] provided a conservative closed-form solution to determine the failure envelope for skirted spudcans. Then, this solution has a reasonable agreement with the results of the FEM.

Zhang and Shi (2014) [8] discussed the deformation law for a circular foundation based on the FEM, it is concluded that the horizontal load $\mathrm{H}$ and moment load $\mathrm{M}$ have a strong coupling effect on the deformation mode.

In this research, the bearing characteristics of diaphragm wall foundation under the combined load of vertical ( $V$ ), horizontal $(H)$ and moment $(M)$ are studied based on the FEM. Then, the results are compared with solutions of theoretical models.

\section{Numerical modeling}

2.1. Foundation model and soil properties

In this study, the establishment of numerical simulation model and the determination of parameters are based on an engineering case. Sufficient boreholes were sunk to obtain details of the soil layers distributions. Then, the plane dimension diagram and detailed soil distribution of the diaphragm wall foundation are shown in Figure 1. 


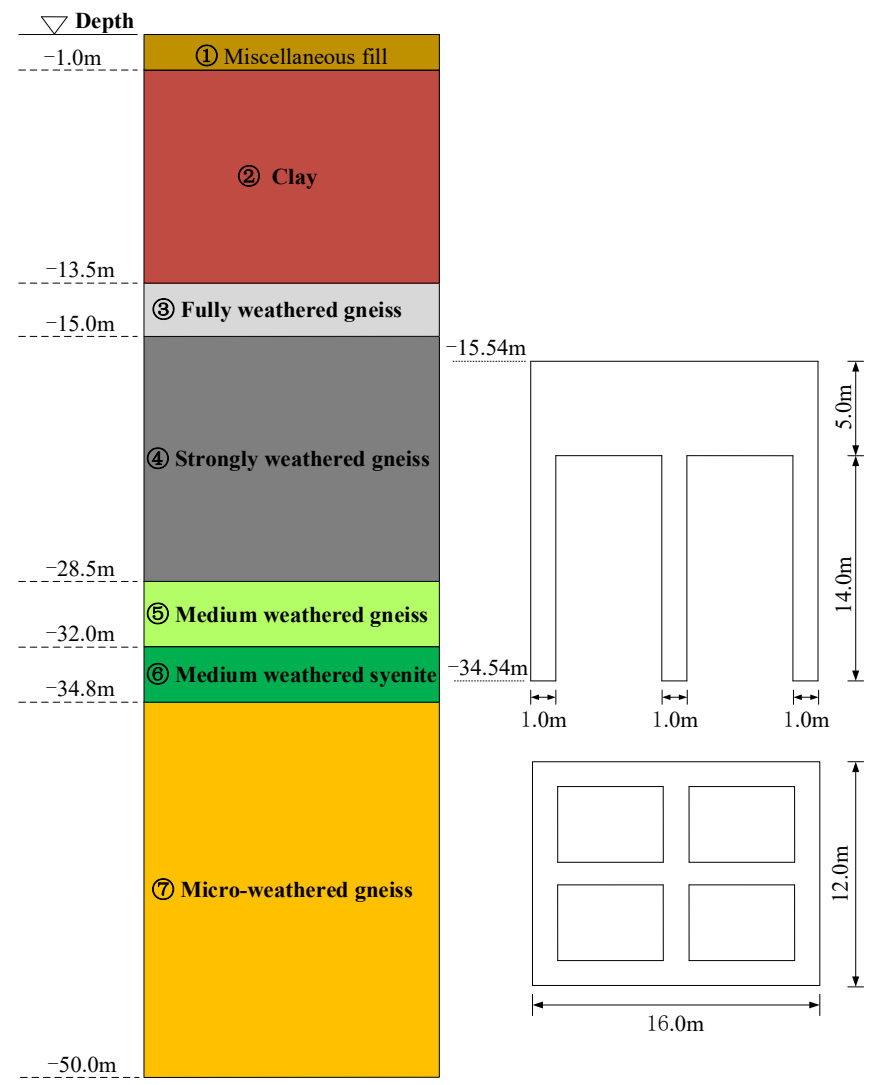

Figure 1. Soil distribution and details of foundation

The diaphragm wall foundation model is $12.0 \mathrm{~m} \times 16.0 \mathrm{~m}$, wall thickness is $1.0 \mathrm{~m}$, cushion cap is $5.0 \mathrm{~m}$ thick, and foundation embedded depth is $19.0 \mathrm{~m}$. In addition, there is $15.54 \mathrm{~m}$ soil layer above the foundation. Then, the soil was modeled as a linear elasticperfectly plastic model, governed by the Mohr-Coulomb criterion. Furthermore, the detailed soil profiles are listed in Table 1, in which $\varphi$ is the internal friction angle, $c$ is the Cohesion, E is Young's modulus, then $\mu$ is Possion's ratio.

Table 1. Mechanical parameters of soil layers

\begin{tabular}{|c|c|c|c|c|c|}
\hline $\begin{array}{c}\text { Layer } \\
\text { number }\end{array}$ & Soil type & $\varphi\left({ }^{\circ}\right)$ & $c(\mathrm{kPa})$ & $\begin{array}{c}E \\
(\mathrm{MPa})\end{array}$ & $\mu$ \\
\hline (1) & $\begin{array}{c}\text { Miscellaneous } \\
\text { fill }\end{array}$ & 9 & - & - & - \\
\hline (2) & Clay & 14.4 & 51.7 & 10.9 & 0.35 \\
\hline (3) & $\begin{array}{c}\text { Fully } \\
\text { weathered } \\
\text { gneiss }\end{array}$ & 12.7 & 109.6 & 18.3 & 0.46 \\
\hline (4) & $\begin{array}{l}\text { Strongly } \\
\text { weathered } \\
\text { gneiss }\end{array}$ & 40.7 & 665 & 300 & 0.40 \\
\hline (5) & $\begin{array}{l}\text { Medium } \\
\text { weathered } \\
\text { gneiss }\end{array}$ & 48.5 & 875 & 1950 & 0.33 \\
\hline (6) & $\begin{array}{l}\text { Medium } \\
\text { weathered } \\
\text { syenite }\end{array}$ & 62.0 & 1000 & 5300 & 0.36 \\
\hline (7) & $\begin{array}{c}\text { Micro- } \\
\text { weathered } \\
\text { gneiss }\end{array}$ & 56.3 & 1085 & 7700 & 0.35 \\
\hline
\end{tabular}

The diaphragm wall foundation material was reinforced concrete. Concrete was modeled as a linear elastic model, with Young's modulus $(E)$ of $10.05 \mathrm{GPa}$, Possio's ratio $(\mu)$ of 0.17 , and the unit weight $(\gamma)$ of $25.0 \mathrm{kN} / \mathrm{m} 3$. The interface between the foundation and the soil was treated as contact, and detachment was allowed between the foundation and soil. Three-dimensional 8-node linear brick elements with reduced integration were used (C3D8R) for the model. The discretized model area had a side length of 4 times of the diaphragm wall, $50.0 \mathrm{~m}$ in longitudinal depth. With these model dimensions, the calculated behavior of the diaphragm wall foundation is not significantly influenced by the boundaries [9]. Thus, the numerical model was constructed, as shown in Figure 2.

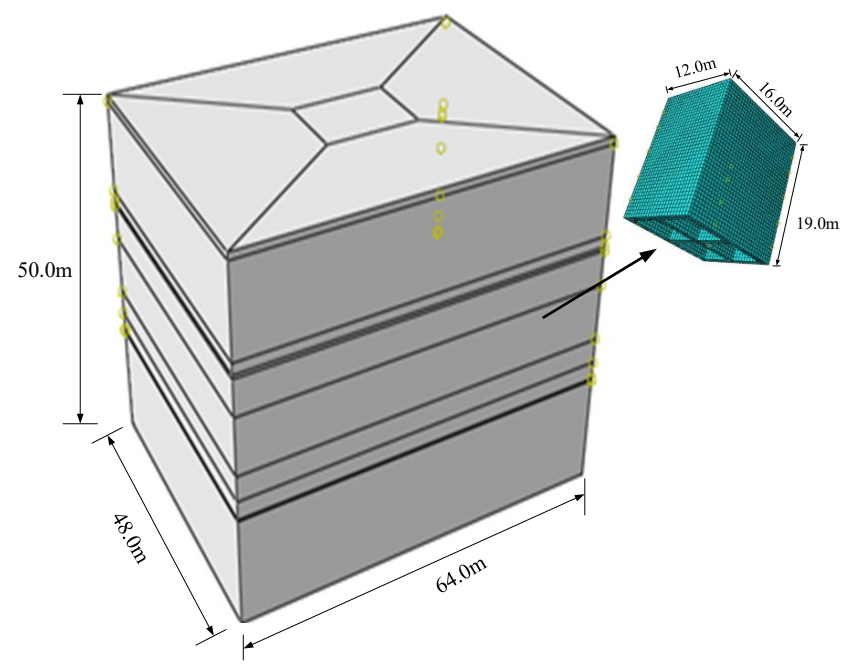

Figure 2. Simulation model

\subsection{Loading path}

The load values of the numerical simulation are listed in Table 2, where $\mathrm{V}$ is the vertical load, $\mathrm{H}$ is the horizontal load, and $\mathrm{M}$ is the overturning moment.

Table 2. Values of applied load

\begin{tabular}{lccc}
\hline Load direction & $V(\mathrm{kN})$ & $H(\mathrm{kN})$ & $M(\mathrm{kN} \cdot \mathrm{m})$ \\
\hline value & 68475 & 65521 & 183676 \\
\hline
\end{tabular}

\subsubsection{Vertical load}

First of all, the load $V$ was applied in vertical direction. During the construction of the diaphragm wall foundation, the concrete was poured by trenching in situ. In this process, the soil inside the closed wall will not be removed. Therefore, the internal soil mass was surrounded by a closed wall to form a relatively closed "soil core". Due to the existence of soil core in the wall, the mobilization mechanism, distribution and calculation method of side resistance inside the wall will be complicated, which becomes the focus and difficulty of bearing characteristics of the diaphragm wall foundation.

The closed wall foundation and the cap are combined to form an integral structure, which is regarded as the "skeleton" in the soil. Thus, the foundation and the soil inside and outside the wall can be borne the load coordinately.

As shown in Figure 3, the vertical load of diaphragm wall foundation is borne by inner side resistance, outer side resistance, resistance of soil core and resistance at the end of wall respectively. Furthermore, it can be observed from Figure 3 that the end resistance and the resistance of soil core account for a large proportion of the vertical load. However, the proportions of inner and outer side resistance are few. Additionally, the side resistance of diaphragm wall foundation increases gradually, while the resistance borne by soil core decreases gradually. Due to the increase of vertical load, the side resistance outside the foundation is constantly mobilized, and the compression of soil core is increasing. Finally, the sum of end resistance and soil core resistance accounts for about $75 \%$ of the vertical load. 


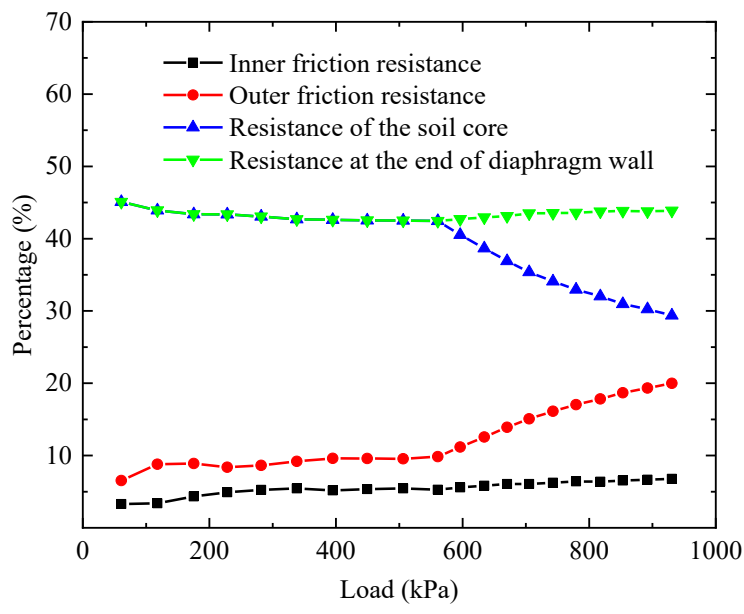

Figure 3. Distribution percentage curve of vertical load

The displacement curves at various depths of the diaphragm wall foundation and its surrounding and internal soil under the ultimate load are further plotted in Figure 4. As shown in Figure 4, the settlement of the soil core is basically synchronous with that of the foundation itself, thus, the soil core has the smaller compression. However, the soil near the bottom of the wall end has the larger displacement. Moreover, the settlement of the soil below the bottom of the core decreases nonlinearly along the depth. Furthermore, it can be concluded that the instability mode of the diaphragm wall foundation under the vertical load is the overall shear failure that the compaction area is formed at the bottom of the foundation.

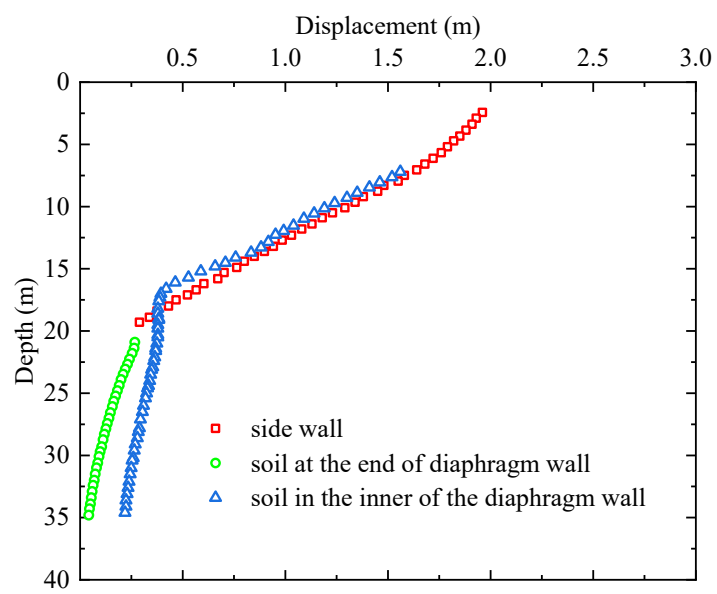

Figure 4. Displacement curve at various depths of the diaphragm wall and soil

In addition, Figure 5 is the curve plotted by the values of the inner side resistance and the outer side resistance at various depths. The mobilization of side friction resistance is caused by the relative displacement between foundation and soil.

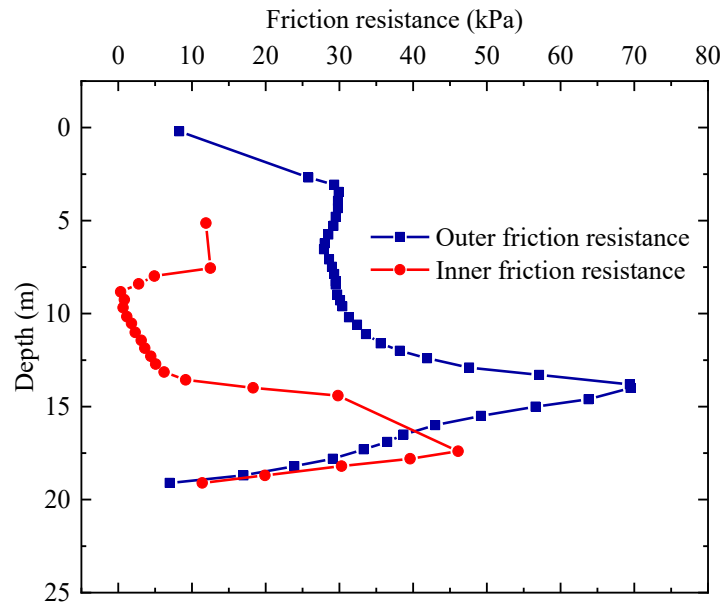

Figure 5. Friction resistance at various depths of the soil

It can be obtained from Figure 5 that the mobilization mechanism of inner side resistance and outer side resistance of the diaphragm wall foundation is different. The inner friction resistance is the bottom-up mobilization characteristic, while the mobilization of outer side resistance is in the opposite direction. This is due to the different boundary conditions and displacement modes of the soil inside and outside the wall. The deformation mode of the soil outside the wall is mainly shear deformation. The diaphragm wall foundation under vertical load, the relative displacement between the foundation and the soil outside the wall increases gradually from top to bottom, so the corresponding outer side resistance is mobilized from top to bottom. On the other hand, the soil core and the foundation will sink synchronously at the initial stage. With the increase of load, the resistance at the bottom of the soil core increases, the upward displacement of the soil core relative to the wall will be caused, so the inner side resistance is mobilized from the bottom to the top.

\subsubsection{Combined load}

Under the combined load of $\mathrm{V}-\mathrm{H}-\mathrm{M}$, the bearing characteristics of diaphragm wall foundation were analyzed. Among them, $\mathrm{V}=68475$ $\mathrm{kN}, \mathrm{H}=65521 \mathrm{kN}, \mathrm{M}=183675 \mathrm{kN} \cdot \mathrm{m}$. According to the parameters listed in Table 2, the numerical model of diaphragm wall under combined load was established. Then, the results of mises stress nephogram are shown in Figure 6.
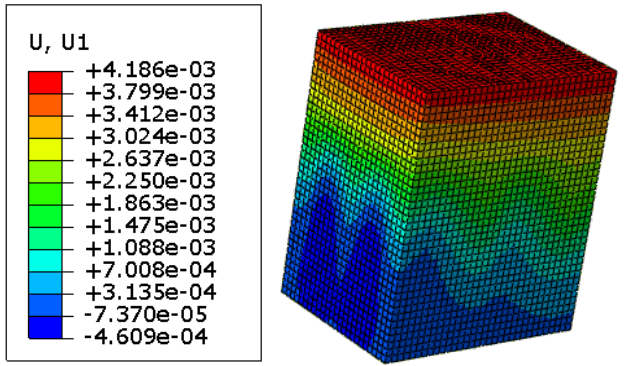

(a)
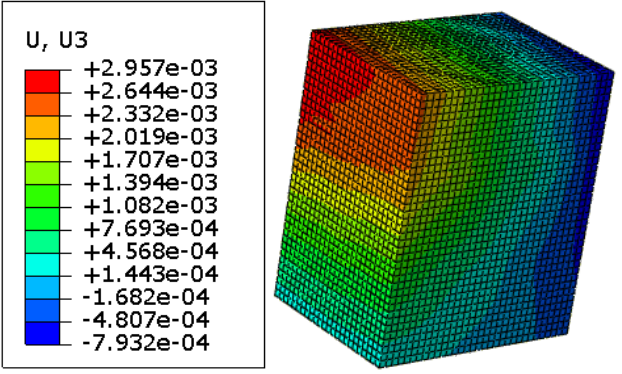

(b)

Figure 6. Mises stress nephogram. a. Horizontal displacement nephogram b. Vertical displacement nephogram 
Therefore, the curve between the horizontal displacement at the top of the foundation and the horizontal load is shown in Figure 7. It can be observed from Figure 7 that the maximum horizontal displacement of the foundation is $4.61 \mathrm{~mm}$.

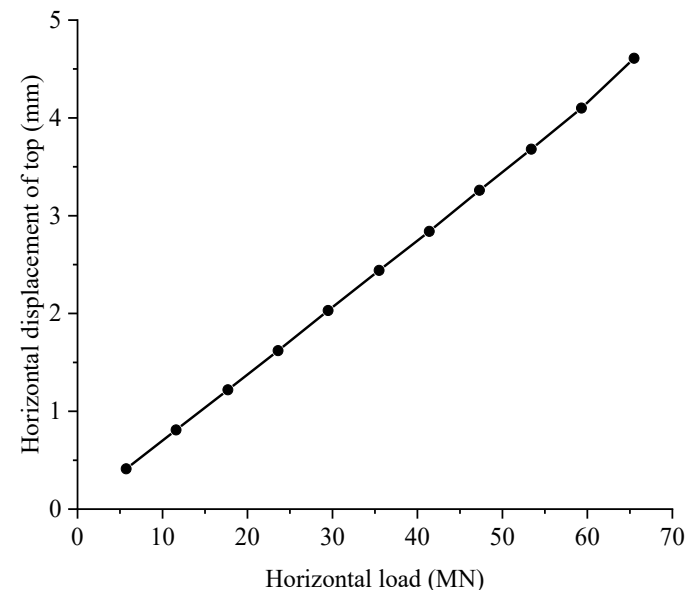

Figure 7. Horizontal displacement of foundation under combined load

Additionally, the horizontal displacement of the foundation at various depths in the final stage of the combined load is shown in Figure 8.

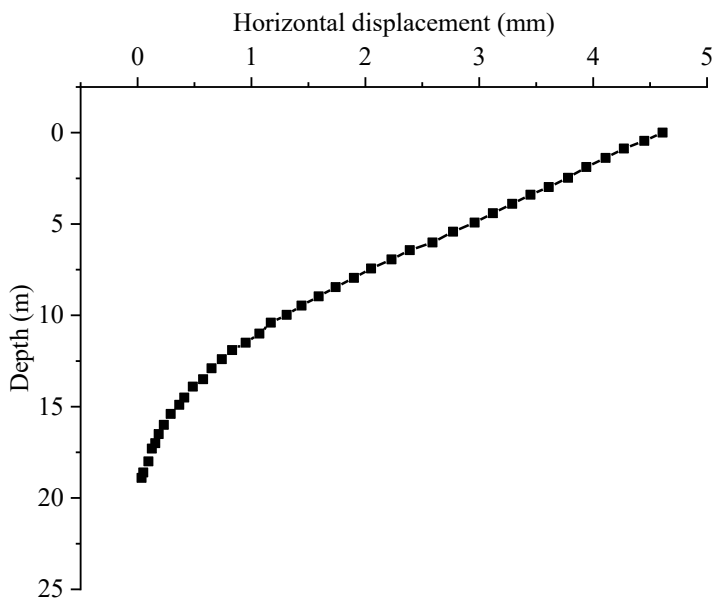

Figure 8. Horizontal displacement of foundation at various depths under combined load

It can be observed from Figure 7 that the horizontal displacement of the foundation increases due to the continuous application of loads, and no obvious inflection point appears in this curve. Then, it can be obtained from figure 8 that the foundation rotates at a point at the end. In summary, it is concluded that the foundation under combined load has the characteristics of overall overturning failure.

Moreover, the vertical displacement caused by horizontal loads is shown in Figure 9.

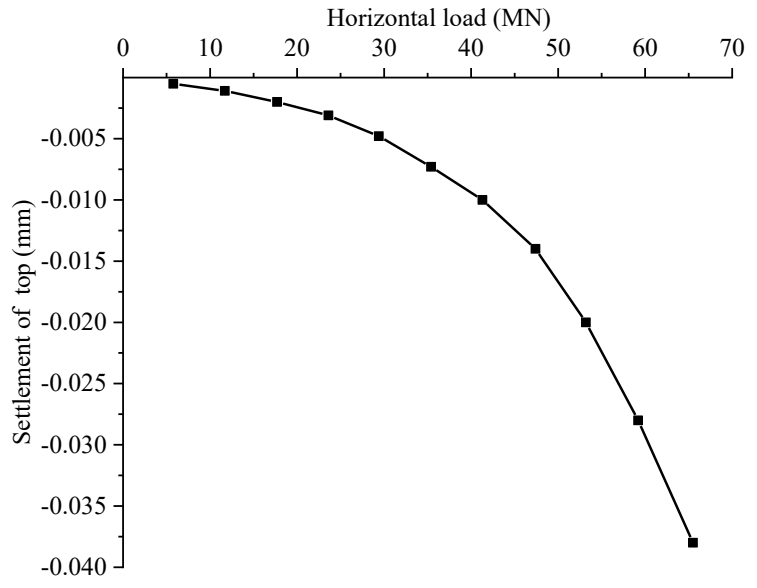

Figure 9. Settlement of foundation under horizontal load

It can be observed from Figure 9 that the foundation settlement increases with the application of horizontal load. It is concluded that the horizontal load has an amplification effect on the settlement of the foundation.

\section{Theoretical model}

\subsection{Eight-component Winkler-beam model}

The Eight-component Winkler spring model, proposed by Sun (1992) [10], was adopted to simulate the soil reactions on the diaphragm wall foundation. Then, the Winkler-beam model and the soil spring elements, were applied to simulate the diaphragm wall-soil system.

As shown in Figure 10(a), in this model, eight types of spring are used to simulate the different components of the soil reactions acting on the diaphragm wall with an equivalent rectangular section of width $B$ (perpendicular to the direction of lateral loading) and length $A$ (parallel to the direction of lateral loading).Springs $k_{\theta}$ and $k_{\mathrm{s}}$ represent the horizontal subgrade reaction and vertical shear stress on the outer of the diaphragm wall, respectively; springs $k_{\mathrm{v}}$ and $k_{\mathrm{c}}$ represent the normal shear stress and the horizontal shear stress on the end of the diaphragm wall, respectively; springs $k_{\mathrm{s}}$ is the horizontal shear stress on the outer sides of the diaphragm wall. Correspondingly, springs $a k_{\theta}$ and $\varepsilon k_{s}$ represent the horizontal subgrade reaction and vertical shear stress on the inner of the diaphragm wall, respectively: springs $\beta k_{\mathrm{s}}$ is the horizontal shear stress on the inner sides of the diaphragm wall. Furthermore, $\alpha, \beta, \varepsilon$ are all reduction factors less than 1.0. Figure 10(b) shows the mechanical calculation model of the Eight-component Winkler spring model. The rotation angle of the foundation around a point on the central axis is determined as $\theta$. Then, $h$ represents the effective height of resistance of soil inside the foundation. Thus, $h$ can be taken as half of the embedded depth of the foundation for non seismic forces. Additionally, the horizontal shear stress $\left(k_{\mathrm{s}}\right)$ on the sides of the wall and the vertical shear stress $\left(k_{\mathrm{s}}\right)$ of the front and rear walls are constant. While the horizontal shear stress $\left(k_{\theta}\right)$ is expressed to be a function of depth $(y)$ as follows:

$$
k_{\theta}=m\left(z_{0}+y\right)\left[\mathrm{kN} / \mathrm{m}^{3}\right]
$$

where $m$ is the proportional coefficient of $k_{\theta}\left(\mathrm{kN} / \mathrm{m}^{4}\right), z_{0}$ is the distance from the top of the foundation to the ground(m).

For multi-layer soil, the function of $m$ is as follows:

$$
m=\frac{1}{L^{2}} \sum_{i=1}^{n} m_{i} l_{i}\left(l_{i}+2 \sum_{j=1}^{i-1} 2 l_{j}\right)
$$

where $l_{i}$ and $l_{j}$ are the thickness of each layer of soil(m), $L$ is the depth of the foundation embedded in the soil(m). 


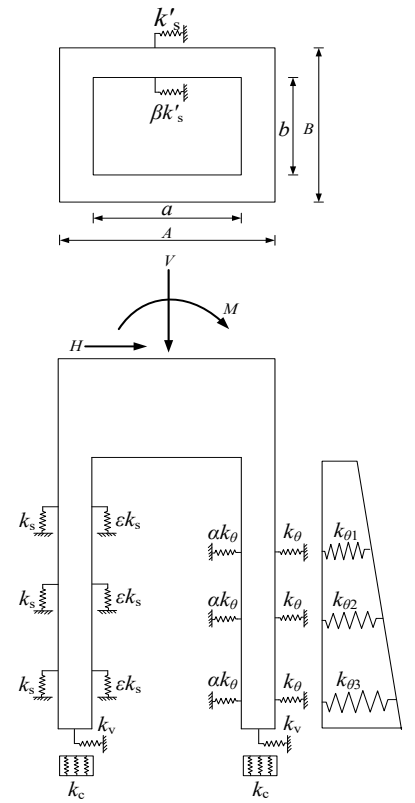

(a)

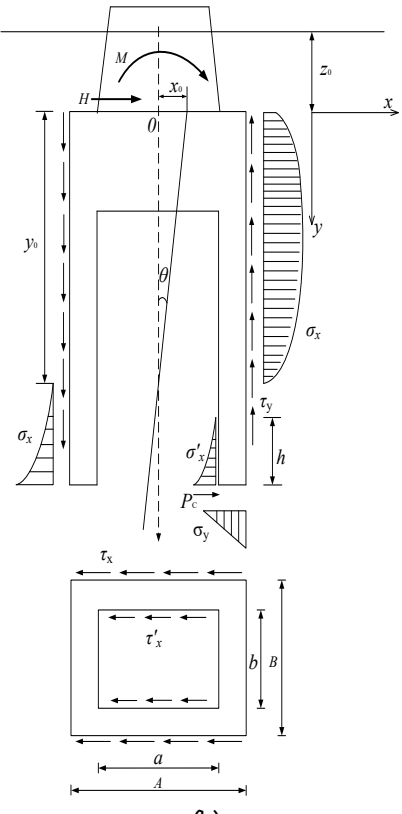

(b)

$$
\begin{array}{r}
J=\frac{1}{8} k_{v}\left(A^{2} B-a^{2} b\right) \\
\lambda=L-h \\
\eta=\frac{a b_{0}}{B_{0}} \\
\xi=\frac{\beta a_{0}}{A_{0}} \\
B_{0}=B+1 \\
A_{0}=A \\
b_{0}=b \\
a_{0}=a
\end{array}
$$

where $a_{0}, b_{0}, A_{0}, B_{0}$ are the calculated widths of the inner side, inner front, outer side and outer front of the foundation respectively(m); $a$ $b, A$ and $B$ are the lengths of the inner side, inner front, outer side, and outer front of the foundation respectively $(\mathrm{m}) ; P_{C}$ is the horizontal friction at the end of the foundation $(\mathrm{kN}) ; \sigma_{x}$ and $\sigma_{x}^{\prime}$ are the normal stresses on the outside and inside of the foundation, respectively $(\mathrm{kPa})$ $\tau_{x}$ and $\tau_{x}^{\prime}$ are the shear stresses on the outside and inside of the foundation, respectively $(\mathrm{kPa}) ; y_{0}$ is the distance from the top of the foundation to the point of rotation(m).

\subsection{Case calculation}

In this study, calculation theory of the Eight-component Winkler spring model and calculation model of rigid pile displacement included in the Chinese standard JTG D63-2007(Ministry of Transport of the People's Republic of China) [11] are used to analyze the horizontal displacement of this project.

According to the mechanics calculation model shown in Figure. 10(b), the following two equilibrium equations can be listed.

$$
\begin{gathered}
\left\{\begin{array}{c}
\sum F_{x}=0 \\
\sum M_{n}=0
\end{array}\right. \\
\left\{\begin{array}{c}
H+P_{C}-\int_{0}^{L} \sigma_{x} B_{0} d y-2 \int_{0}^{L} \tau_{x} A_{0} d y-\int_{L-h}^{L} \alpha \sigma_{x} b_{0} d y- \\
2 \int_{L-h}^{L} \beta \tau_{x} a_{0} d y=0 \\
M+H y_{0}-\int_{0}^{L} \sigma_{x} B_{0}\left(y_{0}-y\right) d y-2 \int_{0}^{L} \tau_{x} A_{0}\left(y_{0}-y\right) d y- \\
\int_{L-h}^{L} \alpha \sigma_{x} b_{0}\left(y_{0}-y\right) d y-2 \int_{L-h}^{L} \beta \tau_{x} a_{0}\left(y_{0}-y\right) d y-P_{C}\left(L-y_{0}\right)- \\
2 \int_{0}^{L} \frac{A^{2}}{4} \theta k_{S} B d y-\int_{0}^{\frac{a}{2}} \theta x^{2} k_{c}(B-b) d x-\int_{\frac{a}{2}}^{\frac{A}{2}} \theta x^{2} k_{c} B d x=0 \\
\sigma_{x}=m\left(z_{0}+y\right)\left(y_{0}-y\right) \theta \\
\tau_{x}=k_{s}^{\prime} \theta\left(y_{0}-y\right)
\end{array}\right.
\end{gathered}
$$

By integrating the above formula and solving them simultaneously, the following results can be obtained.

$$
\left\{\begin{array}{c}
\theta=\frac{t_{1} H+t_{2} M}{t_{2} t_{3}-t_{1}^{2}} \\
y_{0}=\frac{t_{3}}{t_{1}}-\frac{M}{\theta t_{1}} \\
x_{0}=\theta y_{0}
\end{array}\right.
$$

$$
\begin{gathered}
t_{1}=\frac{1}{3} m B_{0}\left[(1+\eta) L^{3}-\eta \lambda^{3}\right]+\frac{1}{2} m B_{0} z_{0}\left[(1+\eta) L^{2}-\eta \lambda^{2}\right]+ \\
A_{0} k_{s}^{\prime}\left[(1+\xi) L^{2}-\xi \lambda^{2}\right]-J \\
t_{2}=\frac{1}{2} m B_{0}\left[(1+\eta) L^{2}-\eta \lambda^{2}\right]+m B_{0} z_{0}[(1+\eta) L-\eta \lambda]+ \\
2 k_{s}^{\prime} A_{0}[(1+\xi) L-\xi L] \\
t_{3}=\frac{1}{4} m B_{0}\left[(1+\eta) L^{4}-\eta \lambda^{4}\right]+\frac{1}{3} m B_{0} z_{0}\left[(1+\eta) L^{3}-\eta \lambda^{3}\right]+ \\
\frac{2}{3} A_{0} k_{s}^{\prime}\left[(1+\xi) L^{3}-\xi \lambda^{3}\right]+\frac{W}{4} A k_{c}+\frac{A}{2} k_{s} B L+J L \\
P_{C}=J \theta
\end{gathered}
$$

\subsubsection{Calculation theory of the Eight-component Winkler spring model}

Based on the project case, the detailed parameters required for the analysis are listed in Table 3.

Table 3. Calculation parameters of Eight-component Winkler spring model

\begin{tabular}{llc}
\hline Parameter & value & unit \\
\hline$A$ & 16 & $\mathrm{~m}$ \\
$B$ & 12 & $\mathrm{~m}$ \\
$a$ & 13 & $\mathrm{~m}$ \\
$b$ & 9 & $\mathrm{~m}$ \\
$L$ & 19 & $\mathrm{~m}$ \\
$h$ & 7 & $\mathrm{~m}$ \\
$a$ & 0.2 & - \\
$\beta$ & 0.2 & - \\
$k_{\mathrm{s}}$ & 12 & $\mathrm{MN} / \mathrm{m}^{3}$ \\
$k_{\mathrm{s}}$ & 12 & $\mathrm{MN} / \mathrm{m}^{3}$ \\
$k_{c}$ & 3318.188 & $\mathrm{MN} / \mathrm{m}^{3}$ \\
$m$ & 59.61 & $\mathrm{MN} / \mathrm{m}^{4}$ \\
\hline Based & on & the above formulas, the rotation angle and horizontal
\end{tabular}

Based on the above formulas, the rotation angle and horizontal displacement at the top of the foundation were calculated as follows:

$$
\left\{\begin{array}{c}
\theta_{E}=1.08 \times 10^{-4} \mathrm{rad} \\
x_{E}=2.06 \mathrm{~mm}
\end{array}\right.
$$

where $\theta_{E}$ is the rotation angle at the top of the foundation(rad); $\boldsymbol{x}_{E}$ is the horizontal displacement at the top of the foundation(mm).

Then, the horizontal displacement values of the variation depths along the diaphragm wall foundation obtained by the mechanical model are plotted in Figure 11. 


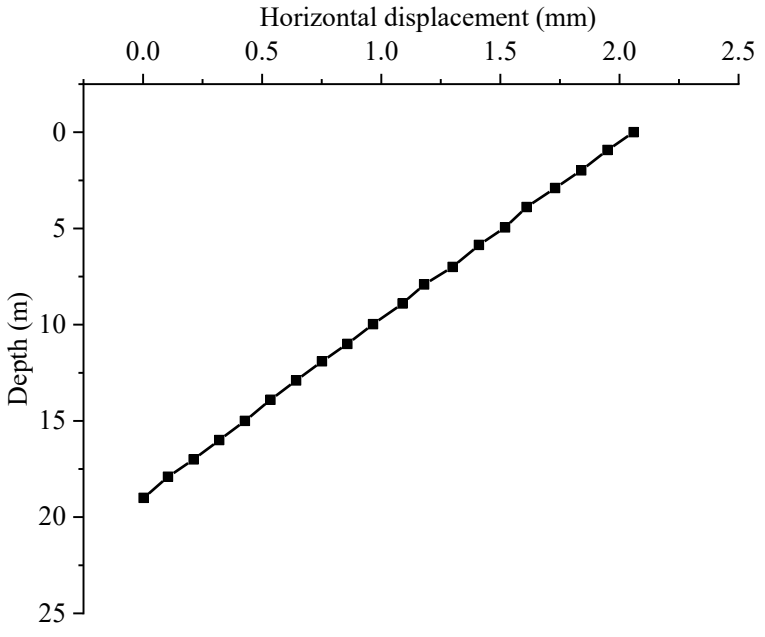

Figure 11. Calculation results of Eight-component Winkler spring model

\subsubsection{Calculation model of rigid pile displacement}

Based on the calculation model of rigid pile displacement included in the Chinese standard JTG D63-2007(Ministry of Transport of the People's Republic of China) [11], the detailed calculation parameters are listed in Table 4.

Table 4. Calculation parameters of calculation model of rigid pile displacement

\begin{tabular}{llc}
\hline Parameter & value & unit \\
\hline$E I$ & $4.893 \times 10^{10}$ & $\mathrm{kN} \cdot \mathrm{m}^{2}$ \\
$m^{\prime}$ & $36.25 \times 10^{3}$ & $\mathrm{kN} / \mathrm{m}^{4}$ \\
$\beta^{\prime}$ & 0.3 & - \\
$\lambda^{\prime}$ & 21.8 & $\mathrm{~m}$ \\
$W_{0}$ & 254.844 & $\mathrm{~m}^{3}$ \\
\hline
\end{tabular}

where $E I$ is the bending stiffness of foundation $\left(\mathrm{kN} \cdot \mathrm{m}^{2}\right) ; m^{\prime}$ is in accordance with Chinese standard JTG D63-2007(Ministry of Transport of the People's Republic of China) [11]; $\beta^{\prime}$ is the ratio of shear proportional coefficient to vertical proportional coefficient at a certain depth; $\lambda$ 'is the ratio of the total bending moment on the bottom of the foundation to the resultant horizontal force; $W_{o}$ is the edge elastic moment of foundation bottom.

The calculation procedures and formulas are all in accordance with the Chinese standard JTG D63-2007(Ministry of Transport of the People's Republic of China) [11], the results are further obtained as below.

$$
\left\{\begin{array}{c}
\theta_{S}=1.735 \times 10^{-4} \mathrm{rad} \\
x_{S}=3.30 \mathrm{~mm}
\end{array}\right.
$$

where $\theta s$ and $x_{s}$ are the rotation angle and horizontal displacement at the top of the foundation respectively.

Similarly, the horizontal displacement values of the variation depths along the diaphragm wall foundation obtained by this method are shown in Figure 12.

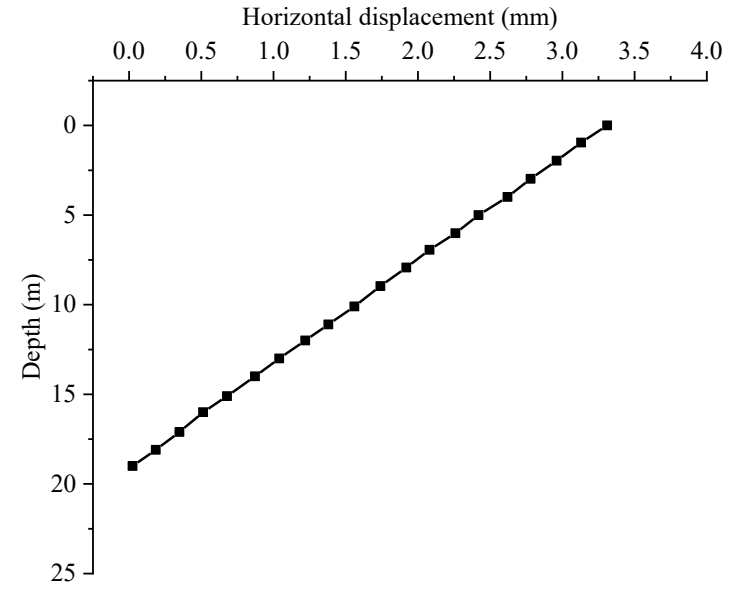

Figure 12. Calculation results of JTG D63-2007

\section{Analysis and discussion of results}

Based on the numerical simulation, Eight-component Winkler spring model and the calculation model of rigid pile displacement, the results of these three different methods are shown in Figure 13.

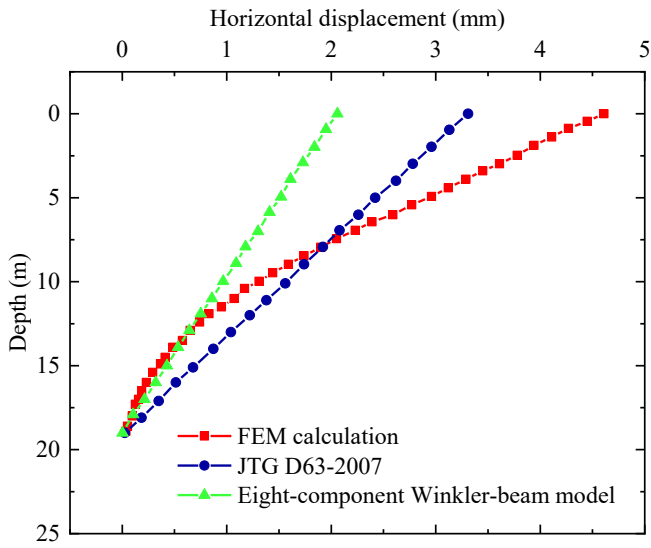

Figure 13. Horizontal displacement of foundation at various depths under three methods

It can be observed from Figure 13 that the horizontal displacements calculated by the three methods are highly coincident, which shows that the above three methods have a properly applied for this case. It also proves that the methods of Eight-component Winkler spring model and the calculation model of rigid pile displacement are suitable for calculating and analyzing the displacement characteristics of diaphragm wall foundation. In addition, it can also be concluded from Figure 13 that the foundation of diaphragm wall rotates at a point at the end of the wall, and the foundation is characterized by overall overturning failure under combined load. It further shows that the foundation of diaphragm wall has large rigidity and high bearing capacity.

\section{Conclusion}

In this paper, based on the case of a diaphragm wall foundation project, the finite element analysis software ABAQUS was used to establish the 3D finite element calculation models, thus, the bearing characteristics of diaphragm wall foundation under vertical load and combined load were discussed. Furthermore, the results of numerical simulation were compared and verified by the calculation model of rigid pile displacement included in the Chinese standard JTG D63- 
2007 and the Eight-component Winkler spring model. The following conclusions can be drawn.

(1) The vertical load of the diaphragm wall foundation is borne by the four parts of resistance of inner friction, outer friction, soil core and the end of wall respectively. Then, the sum of end resistance and soil core resistance accounts for about $75 \%$ of the vertical load. Moreover the mobilization mechanism of inner side resistance and outer side resistance of the diaphragm wall foundation is different under the vertical load, that is, the inner side resistance is the bottom-up mobilization characteristic, while the mobilization of outer side resistance is in the opposite direction. Additionally, the instability mode of the diaphragm wall foundation is the overall shear failure.

(2) The diaphragm wall foundation has the characteristics of overall overturning failure under combined load. Furthermore, the horizontal load has an amplification effect on the vertical settlement of the foundation.

(3) The maximum horizontal displacements of diaphragm wall foundation calculated by FEM, rigid pile displacement method and Eight-component Winkler spring model are $4.61 \mathrm{~mm}, 3.30 \mathrm{~mm}$ and $2.06 \mathrm{~mm}$ respectively. Therefore, the results of the numerical simulation properly coincided with that of the calculation model of rigid pile displacement included in the Chinese standard JTG D632007 and the Eight-component Winkler spring model. Moreover, the two models of Eight-component Winkler spring and the rigid pile displacement models are suitable for the calculation and analysis of foundation displacement characteristics in this study.

\section{Nomenclature}

$A$ : The external side length of diaphragm wall foundation

$A_{0}$ : The calculated widths of the outer side

$a$ : The internal side length of diaphragm wall foundation

$a_{0}$ : The calculated widths of the inner side

$B$ : The external front width of diaphragm wall foundation

$B_{0}$ : The calculated widths of the outer front

$b$ : The internal front width of diaphragm wall foundation

$b_{0}$ : The calculated widths of the inner front

$c$ : The Cohesion

$E$ : The Young's modulus

$F_{X}$ : The resultant force in the horizontal direction

$h$ : The effective calculation height inside foundation

$H$ : The load in horizontal direction

$I$ : The moment of inertia

$J$ : The calculation parameters of the Eight-component Winkler spring model

$k_{c}$ : The horizontal proportional coefficient of shear stress on the end of the diaphragm wall

$k_{\mathrm{s}}$ : The vertical proportional coefficient of shear stress on the outer front of the diaphragm wall

$k_{\mathrm{s}}$ : The horizontal proportional coefficient of shear stress on the outer sides of the diaphragm wall

$k_{\mathrm{V}}$ : The normal proportional coefficient of shear stress on the end of the diaphragm wall

$k_{\theta}$ : The horizontal proportional coefficient of shear stress on the outer front of the diaphragm wall

$L$ : The depth of the foundation embedded in the soil

$l_{i}$ : The thickness of $i$ th layer of soil

$l_{j}$ : The thickness of $j$ th layer of soil

$M$ : The moment load

$M_{\mathrm{n}}$ : The summation of moment loads

$m$ : The proportional coefficient of $k$

$m_{i}$ : The proportional coefficient of $i$ th layer of soil

$m^{\prime}$ : The proportional coefficient in accordance with Chinese standard JTG D63-2007(Ministry of Transport of the People's Republic of China) $P_{C}$ : The horizontal friction at the end of the foundation

$t_{1}$ : The calculation parameters of the Eight-component Winkler spring model

$t_{2}$ : The calculation parameters of the Eight-component Winkler spring model

$t_{3}$ : The calculation parameters of the Eight-component Winkler spring model
$V:$ The load in vertical direction

$W_{o}$ : The edge elastic moment of foundation bottom

$x_{0}$ : The horizontal displacement of foundation top

$x_{E}$ : The horizontal displacement of foundation top calculated by the Eight-component Winkler spring model

$x_{S}$ : The horizontal displacement of foundation top calculated by Chinese standard JTG D63-2007

$y$ : The depth

$y_{0}:$ The depth of the rotation point

$z_{0}$ : The distance from the top of the foundation to the ground

$a:$ The reduction factor of $k \theta$

$a k_{\theta}$ : The horizontal proportional coefficient stress on the inner front of the diaphragm wall

$\beta:$ The reduction factor of $k_{\mathrm{s}}$

$\beta k_{\mathrm{s}}$ : The horizontal proportional coefficient of shear stress on the inner sides of the diaphragm wall

$\beta^{\prime}$ : The ratio of shear proportional coefficient to vertical proportional coefficient at a certain depth

$\varepsilon:$ The reduction factor of $k_{\mathrm{s}}$

$\varepsilon k_{\mathrm{s}}$ : The horizontal proportional coefficient shear stress on the inner front of the diaphragm wall

$\phi:$ The internal friction angle

$\sigma_{x}$ : The normal stresses on outer front of the diaphragm wall

$\sigma_{x}^{\prime}$ : The normal stresses on inner front of the diaphragm wall

$\tau_{x}$ : The shear stresses on the outside of the foundation

$\tau_{x}^{\prime}$ : The shear stresses on the inside of the foundation

$\theta_{E}$ : The rotation angle of foundation top calculated by the Eightcomponent Winkler spring model

$\theta_{s}$ : The rotation angle of foundation top calculated by Chinese standard JTG D63-2007

$\lambda$ : The calculation parameters of the Eight-component Winkler spring model

$\lambda^{\prime}$ : The ratio of the total bending moment on the bottom of the foundation to the resultant horizontal force

$\eta$ : The calculation parameters of the Eight-component Winkler spring model

$\xi$ : The calculation parameters of the Eight-component Winkler spring model

$v$ : The Possion's ratio

$\gamma:$ The unit weight

\section{Declaration of Conflict of Interests}

The authors declare that there is no conflict of interest. They have no known competing financial interests or personal relationships that could have appeared to influence the work reported in this paper.

\section{References}

[1.] Taiebat, H.A., Carter, J.P., Numerical studies of the bearing capacity of shallow foundations on cohesive soil subjected to combined loading. Géotechnique 50 (2000) 409-418.

[2.] Wang, D., Xia, J., Failure loci of suction caisson foundations under combined loading conditions. China Ocean Engineering 22 (2008) 455-464.

[3.] Lian, J.J., Sun, L.Q., Zhang, J.F., Wang, H.J., Bearing capacity and technical advantages of composite bucket foundation of offshore wind turbines. Transactions of Tianjin University 17 (2011) 132137.

[4.] Le, C.H., Kim, S.R., Evaluation of vertical and horizontal bearing capacities of bucket foundations in clay. Ocean Engineering 52 (2012) 75-82.

[5.] Liu, M.M., Yang, M., Wang, H.J., Bearing behavior of wide-shallow bucket foundation for offshore wind turbines in drained silty sand. Ocean Engineering 82 (2014) 169-179.

[6.] Fan, Q.L., Zheng, J., Ma, S.L., An investigation of failure envelope for skirted foundations in soft clay based on computer-aided analyses. Wireless Personal Communications 103 (2018) 12191228.

[7.] Vulpe, C., Bienen, B., Gaudin, C., Predicting the undrained capacity of skirted spudcans under combined loading. Ocean Engineering 74 (2013) 178-188. 
[8.] Zhang, Q.Y., Shi, H.D., Study on deformation law of circular foundation under combined loading. Journal of Ocean University of China 13 (2014) 51-56.

[9.] Hung, L.C., Kim, S.R., Evaluation of vertical and horizontal bearing capacities of bucket foundations in clay. Ocean Engineering 52 (2012) 75-82.

[10.] Sun, X.X., Study on calculation method of displacement and internal force of rigid underground closed wall foundation. Chinese Journal of Geotechnical Engineering 14 (1992) 45-52.

[11.] Ministry of Transport of the People's Republic of China (2007) JTG D63-2007 Code for Design of Ground Base and Foundation of Highway Bridges and Culverts. China Communications Press, Beijing.

\section{How to Cite This Article}

Huang, H., Wang, C., Gong, W., Xu, H., Bearing Characteristics of Diaphragm Wall Foundation under Vertical and Combined Load, Civil Engineering Beyond Limits, 1(2022), 1507.

https://doi.org/10.36937/cebel.2022. 1507 